\title{
ANALISIS MODEL PENERIMAAN TEKNOLOGI PROPERTI MANAGEMENT SYSTEM TERHADAP KINERJA MANAJEMEN PADA ERA REVOLUSI INDUSTRI 4.0
}

\author{
Budi Utomo ${ }^{1}$ \\ I.B. Teddy Prianthara ${ }^{2}$ \\ Universitas Pendidikan Nasional ${ }^{1,2}$ \\ Email : utomo.budi1981@gmail.com¹ Ibtp4563@gmail.com²
}

\begin{abstract}
ABSTRAK
Tujuan penelitian ini adalah untuk menganalisis pengaruh budaya kerja terhadap keyakinan atas sistem dan keinovatifan personal, pengaruh keyakinan atas sistem dan keinovatifan personal terhadap persepsi kegunaan dan persepsi kemudahan, pengaruh persepsi kegunaan, persepsi kemudahan dan budaya kerja terhadap kinerja manajemen. Populasi dalam penelitian ini adalah seluruh karyawan Unit Archipelago International Indonesia Area Bali sebanyak 56 orang karyawan. Tujuan penelitian untuk menganalisis pengaruh budaya kerja terhadap keyakinan atas sistem, pengaruh budaya kerja terhadap keinovatifan personal, pengaruh keyakinan atas sistem terhadap persepsi kegunaan, pengaruh keinovatifan personal terhadap persepsi kegunaan. pengaruh keyakinan atas sistem terhadap persepsi kemudahan, untuk menganalisis pengaruh keinovatifan personal terhadap persepsi kemudahan, untuk menganalisis pengaruh budaya kerja terhadap kinerja keuangan. pengaruh persepsi kegunaan terhadap kinerja keuangan. pengaruh persepsi kemudahan terhadap kinerja manajemen. Hasil analisis menunjukkan bahwa budaya kerja berpengaruh positif dan signifikan terhadap keyakinan Keyakinan atas sistem berpengaruh positif dan signifikan dan persepsi kemudahan berpengaruh positif dan signifikan terhadap kinerja manajemen. Sedangkan budaya kerja tidak berpengaruh signifikan terhadap kinerja manajemen.
\end{abstract}

Kata kunci: budaya kerja; keyakinan atas sistem; keinovatifan personal; kinerja manajemen

\section{ABSTRACT}

The purpose of this study was to analyze the influence of work culture on belief in systems and personal innovativeness, the effect of belief in systems and personal innovativeness on perceptions of usefulness and perceived convenience the effect of perceived usefulness, perceived convenience and work culture on management performance. The population in this study were all employees of the Archipelago International Indonesia Area Bali Unit as many as 56 employees. The results of the analysis show that work culture has a positive and significant effect on belief. Belief in the system has a positive and significant effect and perceived convenience has a positive and significant effect on management performance. Meanwhile, work culture has no significant effect on management performance.

Keywords : work culture; system confidence; personal innovation; management performance 


\section{PENDAHULUAN}

Fenomena penurunan jumlah kunjungan wisatawan mancanegara (wisman) ke Bali bertolak belakang dengan jumlah hotel bintang dan non bintang di Bali yang terus mengalami peningkatan. Hal ini menunjukkan adanya kesenjangan antara kenyataan dan kondisi yang diharapkan, yang diperkuat dengan data yang diperoleh dari Badan Pusat Statistik Provinsi Bali pada Tabel 1 sebagai berikut:

Tabel 1.

Jumlah Kunjungan Wisatawan ke Bali per bulan Tahun 2014-2019

\begin{tabular}{lrrrrrr}
\hline \multicolumn{1}{c}{ Bulan / Month } & $\mathbf{2 0 1 4}$ & $\mathbf{2 0 1 5}$ & $\mathbf{2 0 1 6}$ & $\mathbf{2 0 1 7}$ & $\mathbf{2 0 1 8}$ & $\mathbf{2 0 1 9}$ \\
\hline Januari / January & 279 & 301 & 350 & 460 & 358 & 455 \\
& 257 & 748 & 592 & 824 & 065 & 708 \\
Pebruari / February & 275 & 338 & 375 & 453 & 452 & 437 \\
& 795 & 991 & 744 & 985 & 423 & 537 \\
M a r e t / M a r c h & 276 & 305 & 364 & 425 & 492 & 449 \\
& 573 & 272 & 113 & 499 & 678 & 637 \\
A p r i l / A p r i l & 280 & 313 & 380 & 477 & 516 & 477 \\
& 096 & 763 & 767 & 464 & 777 & 125 \\
M e i / M a y & 286 & 295 & 394 & 489 & 528 & 488 \\
& 033 & 973 & 557 & 376 & 512 & 432 \\
J u n i / J u ne & 330 & 359 & 405 & 504 & 544 & 549 \\
& 396 & 702 & 835 & 141 & 550 & 751 \\
J u li / J u ly & 361 & 382 & 484 & 592 & 624 & 604 \\
& 066 & 683 & 231 & 046 & 366 & 493 \\
Agustus / August & 336 & 303 & 438 & 601 & 573 & \\
September / September & 763 & 621 & 135 & 884 & 766 & \\
& 354 & 389 & 445 & 550 & 555 & \\
Oktober / October & 762 & 060 & 716 & 520 & 903 & \\
& 341 & 369 & 432 & 465 & 517 & \\
Nopember / November & 651 & 447 & 215 & 085 & 889 & \\
& 296 & 270 & 413 & 361 & 406 & \\
Desember / December & 876 & 935 & 232 & 006 & 725 & \\
& 347 & 370 & 442 & 315 & 498 & \\
Jumlah / Total : & 370 & 640 & 800 & 909 & 819 & \\
Pertumbuhan / Growth & $\mathbf{3 7 6 6}$ & $\mathbf{4 ~ 0 0 1}$ & $\mathbf{4 9 2 7}$ & $\mathbf{5 6 9 7}$ & $\mathbf{6 0 7 0}$ & $\mathbf{3 4 6 2}$ \\
(\%) & $\mathbf{6 3 8}$ & $\mathbf{8 3 5}$ & $\mathbf{9 3 7}$ & $\mathbf{7 3 9}$ & $\mathbf{4 7 3}$ & $\mathbf{6 8 3}$ \\
\hline Sumber : Badan Pusa & $\mathbf{6 . 2 4}$ & $\mathbf{2 3 . 1 4}$ & $\mathbf{1 5 . 6 2}$ & $\mathbf{6 . 5 4}$ & \\
\hline
\end{tabular}

Sumber : Badan Pusat Statistik Bali, 2019 
Dimana jumlah terbanyak berada di Kabupaten Badung yang berjumlah 1.890 unit hotel non bintang dan 443 unit hotel berbintang. Adanya gap fenomena yang terjadi pada industri pariwisata di Bali yang menunjukkan penurunan persentase pertumbuhan kunjungan wisman, namun terdapat peningkatan pada jumlah hotel, menyebabkan persaingan hotel di Badung semakin ketat.

Dalam upaya mencapai kesuksesan di tengah sengitnya persaingan dalam bisnis perhotelan internasional, maka diperlukan merek yang benar-benar kreatif yang mampu memenuhi dan melampaui harapan tamu. Salah satu hotel management di Bali yang turut merasakan persaingan ketat diantara bisnis perhotelan dan juga mampu mempertahankan eksistensinya di tengah persaingan sengit bisnis perhotelan adalah Archipelago Internasional Hotel Management.

Di tengah ketatnya persaingan bisnis perhotelan pada era revolusi industri 4.0, Archipelago Internasional berhasil mempertahankan eksistensinya dengan mencapai penghargaan Hotel Operator nomor 1 di Indonesia, lalu mampu mempertahankan eksistensinya selama 20 tahun lebih dalam kategori inovasi industri dan pemimpin perhotelan, serta berhasil memperoleh 10 penghargaan Award Winning Brand. Permasalahan yang timbul pada Archipelago akibat revolusi industri 4.0 adalah perangkapan jabatan di section accounting, sehingga Archipelago turut berupaya melakukan update system manajemennya menggunakan properti management system agar lebih mudah digunakan dan lebih berguna untuk mempercepat proses pembuatan laporan manajemennya serrta dapat meminimalisisr masalah rangkap jabatan yang terjadi. Selain itu, Archipelago Internasional juga sering menghadapi kendala-kendala dalam proses 
penyusunan laporan manajemen. Adapun masalah-masalah yang sering muncul pada Archipelago International Indonesia Area Bali diantaranya adalah mengenai konsep clearance account, masalah terkait balancing Account Payable (AP) \& AP Aging dengan General Ledger (GL) Account Receivable (AR) \& AR aging, masalah terkait balancing Stock On Hand (SOH) Inventori dengan GL inventori, masalah terkait standard recipe food dan menu food tidak di update, serta masalah ketidaksesuaian antara Balance Sheet (BS) report dan BS reconciliation.

Fenomena Revolusi Industri 4.0 yang sedang terjadi saat ini mengakibatkan adanya pergeseran pekerjaan dengan mengutamakan penggunaan teknologi, sehingga terjadi pengurangan jumlah tenaga kerja pada suatu divisi. Hal tersebut mengakibatkan adanya perangkapan jabatan di Departemen Accounting sehingga mewajibkan Karyawan Accounting harus mampu memahami dengan baik penggunaan Sistem serta meningkatkan Fungsi Kontrol dari Manager Accounting.

Kendala dan hambatan yang terjadi pada proses penyusunan laporan manajemen tersebut disebabkan oleh berbagai macam faktor, diantaranya seperti kurangnya keyakinan pegawai dalam menguasai sistem teknologi properti management yang digunakan untuk penyusunan laporan manajemen. Selain itu, terdapat sejumlah pegawai yang kesulitan menggunakan sistem dan tidak memahami fungsi-fungsi sistem teknologi properti management sehingga menghambat proses penyusunan laporan manajemen. Kemudian pegawai di bagian accounting juga kurang memiliki tingkat keinofativan personal, yakni kurang mampu mengeksplor kemampuannya dalam menggunakan aplikasi atau 
teknologi properti management system tersebut.

Archipelago Internasional memiliki budaya kerja rutin pada setiap divisi di bagian accounting, yang tertuang dalam Golden Rules dan dapat diringkas pada Things to do Finance Leader. Namun dalam pelaksanaannya seringkali tidak sejalan dengan deadline pekerjaan yang ditentukan. Daftar pekerjaan yang tercantum dalam Things to do Finance Leader yang seharusnya diselesaikan dalam waktu sehari, seperti AP Aging vs Daily Receiving Report oleh bagian Account Payable jadi diselesaikan dalam waktu lebih dari sehari. Kemudian pekerjaan yang seharusnya diselesaikan dalam waktu seminggu seperti balancing FO dan Outlet Clearance oleh General Cashier jadi diselesaikan dalam waktu lebih dari satu minggu. Hal-hal diatas adalah kendala dan hambatan lain yang mengakibatkan laporan keuangan menjadi terlambat atau tidak tepat waktu dan ini berpengaruh terhadap terlambatnya analisa kinerja manajemen.

Berlandaskan pada fenomena permasalahan yang terjadi di Archipelago International Indonesia terkait kurangnya budaya kerja yang disiplin waktu untuk penyelesaian laporan manajemen, kemudian masalah terkait kurangnya keyakinan pegawai atas penggunaan teknologi properti management, lalu kurangnya tingkat inovatif personal, adanya masalah pegawai bagian accounting yang kesulitan dalam penggunaan sistem, serta masalah terkait kinerja manajemen yang tidak maksimal akibat berbagai hambatan, maka penulis tertarik untuk meneliti variabel terkait. Lalu penelitian Chirchir et al. (2019) dan Ganyam \& Ivungu (2019) menemukan hasil bahwa persepsi penggunaan sistem dan persepsi kemudahan penggunaan sistem berpengaruh pada kinerja sistem informasi akuntansi yang 
dihasilkan. Kemudian penelitian Arifin (2014); Djuanda \& Tarigan (2016) menemukan hasil bahwa budaya organisasi berpengaruh signifikan dan positif terhadap kinerja manajemen. Sedangkan penelitian Satyawati \& Suartana (2014) menemukan hasil bahwa terdapat pengaruh negatif antara budaya organisasi terhadap kinerja manajemen.

Berdasarkan adanya fenomena kesenjangan antara kenyataan dan kondisi yang diharapkan (a gap between an actual and a desired ideal state) serta ditemukannya research gap pada penelitian sebelumnya, maka tujuan penelitian ini adalah untuk menganalisis penerimaan Property Management System yang dipengaruh oleh keyakinan atas sistem dan keinovatifan personal terhadap persepsi kegunaan dan persepsi kemudahan, untuk menganalisis pengaruh persepsi kegunaan, persepsi kemudahan dan budaya kerja terhadap kinerja manajemen.

Berdasarkan tinjauan teori dan hasil penelitian terdahulu dan hubungan antar variabel, maka model penelitian dapat digambarkan sebagai berikut :

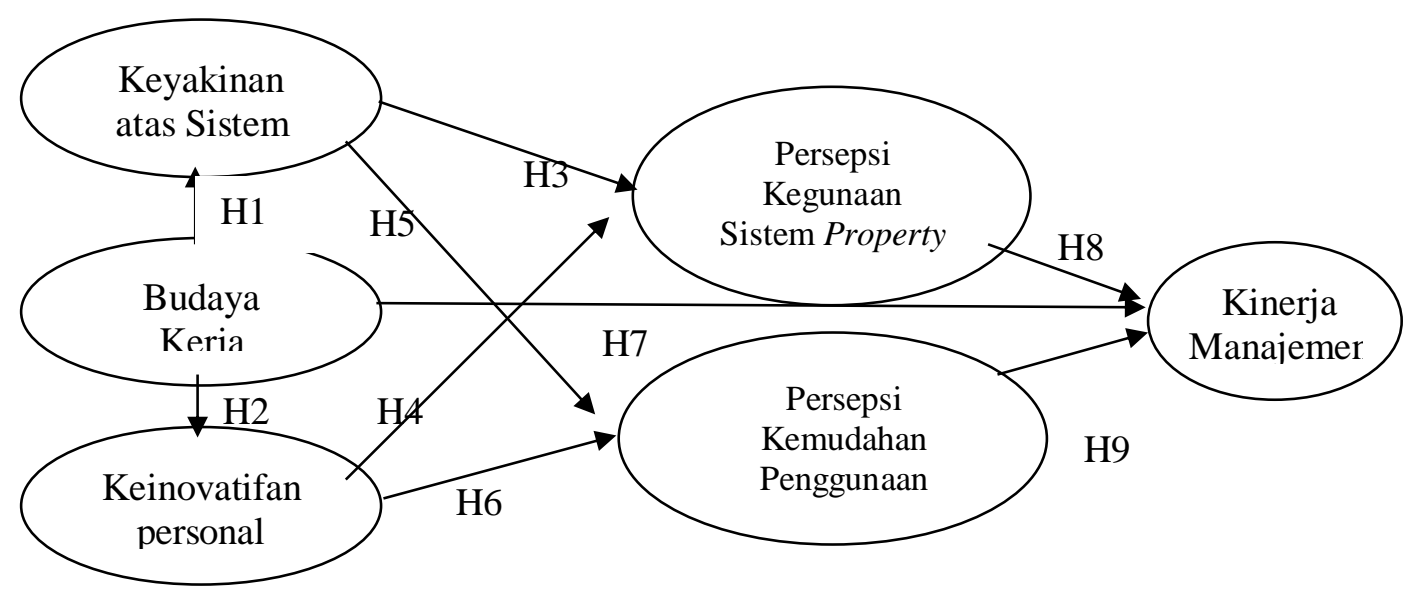

Gambar 1.

Model Kerangka Konseptual 
Berdasarkan beberapa penelitian diatas, maka hipotesis penelitian yang diajukan dalam penelitian ini adalah :

H1 : Semakin baik budaya kerja dalam perusahaan, maka akan semakin meningkatkan keyakinan diri pegawai atas Sistem Property Management yang digunakan oleh perusahaan

H2 : Semakin baik budaya kerja dalam perusahaan, maka akan semakin meningkatkan keinovatifan personal pegawai

H3 : Semakin tinggi keyakinan pegawai atas sistem, maka persepsi pegawai pada kegunaan Sistem Property Management akan semakin meningkat

H4 : Semakin tinggi tingkat keinovatifan personal yang dimiliki pegawai, maka persepsi pegawai pada kegunaan Sistem Property Management akan semakin meningkat

H5 : Semakin tinggi keyakinan pegawai atas sistem, maka persepsi kemudahan penggunaan Sistem Property Management akan semakin meningkat

H6 : Semakin tinggi tingkat keinovatifan personal yang dimiliki pegawai, maka persepsi kemudahan penggunaan Sistem Property Management akan semakin meningkat

H7 : Semakin baik budaya kerja yang dimiliki dalam satu perusahaan, maka kinerja manajemen yang dihasilkan akan semakin meningkat 
H8 : Semakin tinggi persepsi kegunaan Sistem Property Management, maka kinerja manajemen yang dihasilkan akan semakin meningkat

H9 : Semakin tinggi persepsi kemudahan penggunaan Sistem Property Management, maka kinerja manajemen yang dihasilkan akan semakin meningkat

\section{METODE PENELITIAN}

Penelitian ini akan dilakukan pada Unit Archipelago International Indonesia Area Bali. Alasan peneliti melakukan penelitian pada Unit Archipelago International Indonesia Area Bali, karena Archipelago Internasional sering menghadapi kendala-kendala dalam proses penyusunan laporan manajemen, yang disebabkan oleh faktor budaya kerja yang kurang disiplin, kemudian kurangnya keyakinan diri atas sistem yang digunakan perusahaan, kurang memiliki tingkat keinofativan personal serta kurang memiliki persepsi kegunaan dan kemudahan pengunaan Sistem Property Management .

Ruang lingkup penelitian ini adalah seluruh pegawai accounting yang terlibat dalam penyusunan laporan manajemen pada unit Archipelago Internasional Area Bali. Variabel-variabel yang diteliti dalam penelitian ini terdiri dari variabel budaya kerja, keyakinan atas sistem, keinovatifan personal, persepsi kegunaan, persepsi kemudahan dan kinerja manajemen.

Teknik penentuan sampel yang digunakan adalah metode purposive sampling, yaitu metode penentuan sampel dengan pertimbangan bahwa responden merupakan pegawai Archipelago Internasional Area Bali pada bagian accounting 
yang terlibat dalam penyusunan laporan manajemen secara langsung yang sudah bekerja minimal selama satu tahun dan memegang jabatan seperti manager finance, IA/AR, AP/GC dan Cost Control. Penelitian ini menggunakan teknik analisis SEM berbasis component atau variance yaitu PLS Smart. Alasan menggunakan PLS 3.0 adalah membantu peneliti untuk tujuan prediksi.

\section{HASIL DAN PEMBAHASAN}

Pengumpulan data penelitian ini menggunakan kuesioner yang disebarkan secara online menggunakan google form yang dilakukan pada tanggal 27 April 2020 hingga 1 Mei 2020. Berikut data identitas responden berdasarkan jenis kelamin, umur, pendidikan terakhir dan lama bekerja tercantum pada Tabel 2.

Tabel 2.

Karakteristik Responden

\begin{tabular}{|c|c|c|c|c|}
\hline No. & Variabel & Klasifikasi & Jumlah (orang) & Persentase $(\%)$ \\
\hline \multirow{2}{*}{1} & \multirow{2}{*}{ Jenis kelamin } & Laki - laki & 27 & 48,2 \\
\hline & & Perempuan & 29 & 51,8 \\
\hline \multirow{3}{*}{2} & \multirow{3}{*}{ Umur } & 21-30 tahun & 26 & 46,5 \\
\hline & & 31-40 tahun & 20 & 35,9 \\
\hline & & $>40$ tahun & 10 & 18 \\
\hline \multirow{4}{*}{3} & \multirow{4}{*}{$\begin{array}{l}\text { Pendidikan } \\
\text { Terakhir }\end{array}$} & SMA & 7 & 12,5 \\
\hline & & Diploma & 14 & 25,0 \\
\hline & & $\mathrm{S} 1$ & 34 & 60,7 \\
\hline & & S2 & 1 & 1,8 \\
\hline \multirow{4}{*}{3} & \multirow{4}{*}{ Lama kerja } & $<1$ tahun & 2 & 3,6 \\
\hline & & $>1-5$ tahun & 23 & 41,1 \\
\hline & & $>5-10$ tahun & 27 & 48,2 \\
\hline & & $>10$ tahun & 4 & 7,1 \\
\hline
\end{tabular}

Sumber: Data diolah, 2020 
Karakteristik responden yang disajikan pada Tabel 2 menunjukkan bahwa pegawai Archipelago International Indonesia Area Bali pada bagian accounting yang terlibat dalam penyusunan laporan manajemen secara langsung mayoritas adalah pegawai perempuan yang berumur 21-30 tahun. Apabila ditinjau berdasarkan tingkat pendidikan, data menunjukkan bahwa mayoritas responden memiliki jenjang pendidikan akhir pada tingkat Sarjana. Hal ini memiliki makna bahwa Archipelago International Indonesia Area Bali membutuhkan pegawai yang mempunyai pengetahuan dan jenjang pendidikan tinggi khususnya pada bagian accounting yang terlibat dalam penyusunan laporan manajemen, agar dapat mencapai kinerja manajemen perusahaan yang optimal. Pengelompokkan responden berdasarkan lama bekerja menunjukkan bahwa pegawai Archipelago International Indonesia Area Bali mayoritas sudah bekerja selama lebih dari 5 tahun hingga 10 tahun yang menunjukkan bahwa pegawai memiliki rasa loyalitas yang tinggi pada perusahaan.

Untuk menganalisis model penelitian, digunakan metode Partial Least Square (PLS) dengan alat bantu program SmartPLS 3.0. Terdapat dua evaluasi model mendasar dalam pengujian ini yaitu outer model dan inner model. Pengujian inner model dalam PLS dilakukan melalui resampling bootstrap dengan menggunakan 56 sampel. Pada evaluasi model pengukuran atau outer model dilakukan dengan uji Convergent validity, discriminant validity dan composite reliability. 
Berdasarkan Tabel 3 menunjukkan bahwa seluruh nilai outer loading indikator memiliki nilai di atas 0,50 , kemudian nilai AVE seluruh variabel lebih besar dari 0,50 dan cronbachs alpha seluruh variabel penelitian semuanya diatas 0,70. Dengan demikian, dapat disimpulkan bahwa seluruh variabel dalam penelitian ini telah memenuhi persyaratan convergent validity, discriminant validity dan composite reliability.

Tabel 3.

Hasil Convergent Validity, Discriminant Validity dan Composite Reliability

\begin{tabular}{|c|c|c|c|c|}
\hline Variabel & Indikator & $\begin{array}{c}\text { Convergent } \\
\text { Validity (Outer } \\
\text { Loadings) }\end{array}$ & $\begin{array}{c}\text { Discriminant } \\
\text { Validity } \\
(A V E)\end{array}$ & $\begin{array}{c}\text { Composite } \\
\text { Reliability } \\
\text { (Cronbach's } \\
\text { Alpha) } \\
\end{array}$ \\
\hline \multirow{4}{*}{ Budaya kerja (X) } & akteristik dominan & 0,646 & \multirow{5}{*}{0,527} & \multirow{5}{*}{0,779} \\
\hline & Kepemimpinan organisasi & 0,732 & & \\
\hline & ajemen karyawan dalam organisasi & 0,737 & & \\
\hline & ekatan hubungan di dalam organisasi & 0,727 & & \\
\hline \multirow{6}{*}{$\begin{array}{l}\text { Keyakinan atas } \\
\text { sistem }\left(\mathrm{Y}_{1}\right)\end{array}$} & ekanan strategi dalam organisasi & 0,783 & & \\
\hline & nampuan & 0,764 & \multirow{5}{*}{0,686} & \multirow{5}{*}{0,885} \\
\hline & Dukungan perusahaan & 0,823 & & \\
\hline & Percaya pada manfaat sistem & 0,826 & & \\
\hline & Fasilitas & 0,806 & & \\
\hline & $\begin{array}{l}\text { in dapat menyelesaikan pekerjaan } \\
\text { dengan efektif }\end{array}$ & 0,914 & & \\
\hline \multirow{5}{*}{$\begin{array}{l}\text { Keinovatifan } \\
\text { personal }\left(\mathrm{Y}_{2}\right)\end{array}$} & ortunity exploration & 0,836 & \multirow{5}{*}{0,710} & \multirow{5}{*}{0,898} \\
\hline & Generativy & 0,840 & & \\
\hline & Fomative investigation & 0,773 & & \\
\hline & Championing & 0,800 & & \\
\hline & lication & 0,954 & & \\
\hline \multirow{5}{*}{$\begin{array}{c}\text { Persepsi } \\
\text { Kegunaan Sistem } \\
\left(\mathrm{Y}_{3}\right)\end{array}$} & Menjadikan pekerjaan lebih mudah & 0,909 & \multirow{6}{*}{0,800} & \multirow{5}{*}{0,937} \\
\hline & Bermanfaat (usefull) & 0,867 & & \\
\hline & $\begin{array}{l}\text { Menambah produktivitas (increase } \\
\text { productivity) }\end{array}$ & 0,877 & & \\
\hline & $\begin{array}{l}\text { Mempertinggi efektivitas (enhance } \\
\text { efectiveness) }\end{array}$ & 0,959 & & \\
\hline & Mengembangkan kinerja pekerjaan & 0,855 & & \\
\hline \multirow{5}{*}{$\begin{array}{c}\text { Persepsi } \\
\text { Kemudahan } \\
\text { penggunaan } \\
\text { sistem }\left(\mathrm{Y}_{4}\right)\end{array}$} & nya kemudahan dipelajari. & 0,864 & & \multirow{5}{*}{0,888} \\
\hline & Jah dipahami dan dimengerti. & 0,827 & \multirow{4}{*}{0,692} & \\
\hline & lah untuk berinteraksi. & 0,855 & & \\
\hline & Jah untuk digunakan/ dioperasikan & 0,851 & & \\
\hline & eluruhan mudah digunakan & 0,757 & & \\
\hline \multirow{5}{*}{$\begin{array}{c}\text { Kinerja } \\
\text { manajemen }\left(\mathrm{Y}_{5}\right)\end{array}$} & Sales growth & 0,927 & \multirow{5}{*}{0,774} & \multirow{5}{*}{0,926} \\
\hline & Profitability & 0,903 & & \\
\hline & Profit growth & 0,927 & & \\
\hline & Sales margin & 0,858 & & \\
\hline & Manajemen stabil & 0,774 & & \\
\hline
\end{tabular}

Sumber: Data diolah, 2020 
Hasil analisis model empiris penelitian dengan menggunakan alat analisis Partial Least Square 3.0 (PLS) ini dapat dilihat dalam Gambar2 berikut.

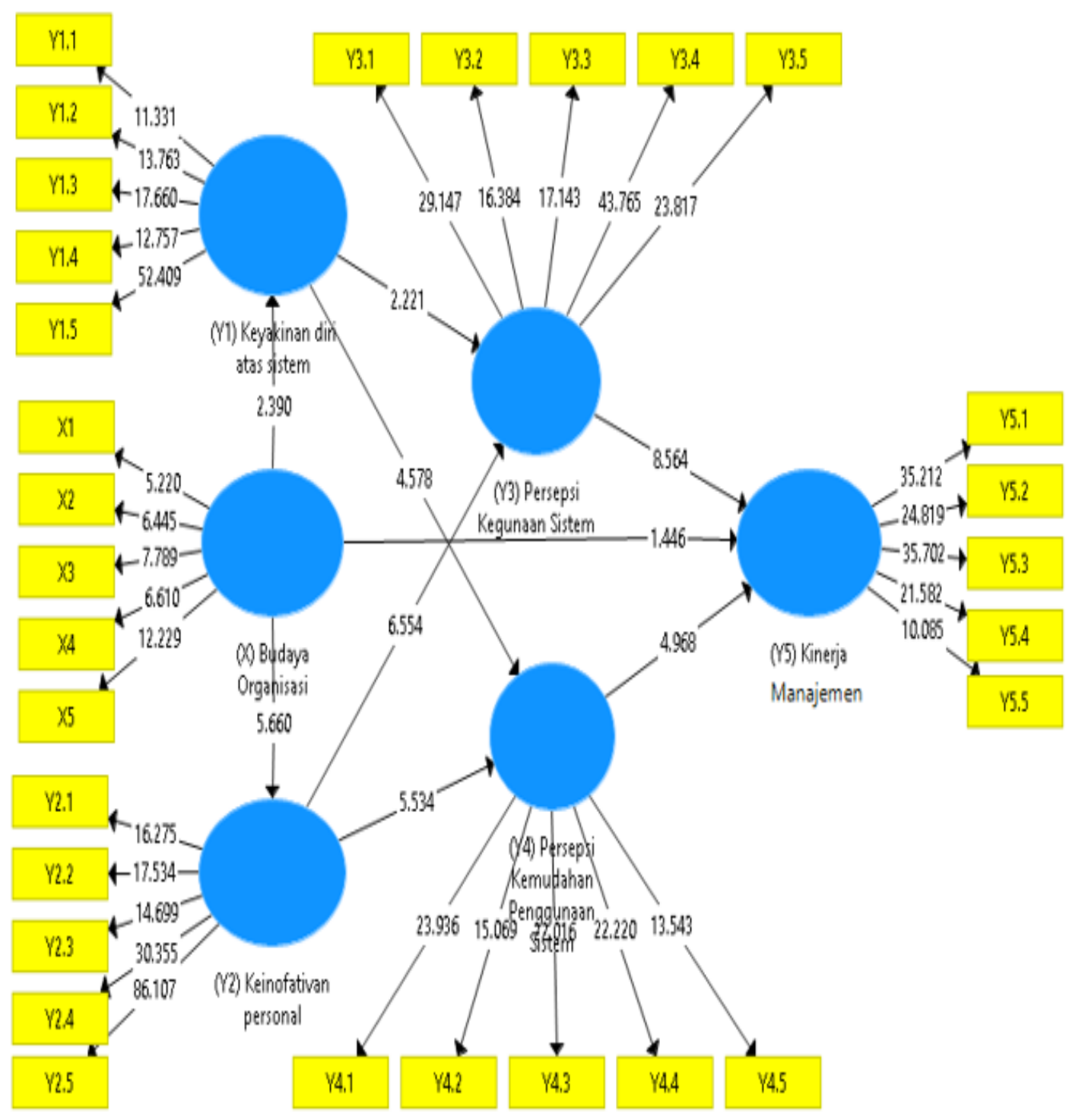

Gambar 2.

Hasil Output PLS 
Pengujian hipotesis pada pengaruh budaya kerja terhadap keyakinan atas sistem (Y1) menghasilkan nilai koefisien jalur sebesar 0,380. Nilai $t$ Statistics didapat sebesar 2,390 (> t kritis 1,96), maka pengaruh budaya kerja terhadap keyakinan atas sistem adalah signifikan. Hal ini menunjukkan bahwa budaya kerja berpengaruh positif dan signifikan terhadap keyakinan atas sistem, dengan demikian Hipotesis pertama (H1) diterima. Hal ini memiliki makna bahwa semakin baik budaya kerja dalam perusahaan, maka akan semakin meningkatkan keyakinan diri pegawai atas Sistem Property Management yang digunakan oleh perusahaan, begitu pula sebaliknya. Penelitian ini mendukung hasil penelitian Suardikha \& Sutrisno (2017), yang memperoleh hasil bahwa budaya memiliki pengaruh yang positif signifikan terhadap keyakinan diri atas sistem.

Pengujian hipotesis pada pengaruh budaya kerja terhadap keinovatifan personal (Y2) menghasilkan nilai koefisien jalur sebesar 0,525. Nilai $t$ Statistics didapat sebesar 5,660 ( $>$ t kritis 1,96), maka pengaruh budaya kerja terhadap keinovatifan personal adalah signifikan. Hal ini menunjukkan bahwa budaya kerja berpengaruh positif dan signifikan terhadap keinovatifan personal, dengan demikian Hipotesis kedua (H2) diterima. Hal ini memiliki makna bahwa semakin baik budaya kerja dalam perusahaan, maka akan semakin meningkatkan keinovatifan personal pegawai, begitu pula sebaliknya. Penelitian ini mendukung hasil penelitian Jan et. al., (2014); Valencia et al., (2017) serta Suardhika \& Sutrisno (2017) yang menemukan hasil bahwa budaya berpengaruh positif dan signifikan terhadap keinovatifan personal. 
Pengujian hipotesis pada pengaruh keyakinan atas sistem terhadap persepsi kegunaan sistem (Y3) menghasilkan nilai koefisien jalur sebesar 0,222. Nilai $t$ Statistics didapat sebesar 2,221 (> t kritis 1,96), maka pengaruh keyakinan atas sistem terhadap persepsi kegunaan sistem adalah signifikan. Hal ini menunjukkan bahwa keyakinan atas sistem berpengaruh positif dan signifikan terhadap persepsi kegunaan sistem, dengan demikian Hipotesis ketiga (H3) diterima. Hal ini memiliki makna bahwa semakin tinggi keyakinan pegawai atas sistem, maka persepsi pegawai pada kegunaan, begitu pula sebaliknya. Penelitian ini mendukung hasil penelitian Diksani dkk., (2014), Zeinabi \& Sheikh (2016) dan Raddaha (2017) yang menyatakan bahwa semakin tinggi keyakinan perawat atas sistem, maka persepsi perawat pada kegunaan sistem akan semakin meningkat.

Pengujian hipotesis pada pengaruh keinovatifan personal terhadap persepsi kegunaan sistem (Y3) menghasilkan nilai koefisien jalur sebesar 0,670. Nilai $t$ Statistics didapat sebesar 6,554 (> t kritis 1,96), maka pengaruh keinovatifan personal terhadap persepsi kegunaan sistem adalah signifikan. Hal ini menunjukkan bahwa keinovatifan personal berpengaruh positif dan signifikan terhadap persepsi kegunaan sistem, dengan demikian Hipotesis keempat (H4) diterima.

Hal ini memiliki makna bahwa semakin tinggi tingkat keinovatifan personal yang dimiliki pegawai, maka persepsi pegawai pada kegunaan Sistem Property Management akan semakin meningkat, begitu pula sebaliknya. 
Penelitian ini mendukung hasil penelitian Diksani dkk., (2014), Binyamin et al., (2016), Suardikha (2017), Oliveira et al., (2017) yang menyatakan bahwa personality karyawan seperti sikap inovatif yang dimiliki karyawan akan mampu mempengaruhi persepsi persepsi penggunan sistem, perilaku dan tingkat kepuasan pengguna.

Pengujian hipotesis pada pengaruh keyakinan atas sistem terhadap persepsi kemudahan penggunaan sistem (Y4) menghasilkan nilai koefisien jalur sebesar 0,468. Nilai $t$ Statistics didapat sebesar 4,578 (> t kritis 1,96), maka pengaruh keyakinan atas sistem terhadap persepsi kemudahan penggunaan sistem adalah signifikan. Hal ini menunjukkan bahwa keyakinan atas sistem berpengaruh positif dan signifikan terhadap persepsi kemudahan penggunaan sistem, dengan demikian Hipotesis kelima (H5) diterima.

Hal ini memiliki makna bahwa semakin tinggi keyakinan pegawai atas sistem, maka persepsi pegawai pada kemudahan penggunaan sistem Property Management akan semakin meningkat, begitu pula sebaliknya. Penelitian ini mendukung hasil penelitian Sudaryono \& Astuti (2015), Suardikha (2017), dan Diksani dkk (2014) yang menemukan hasil bahwa ada pengaruh yang positif dan signifikan antara tingkat keinovatifan personal terhadap persepsi kemudahan penggunaan sistem.

Pengujian hipotesis pada pengaruh keinovatifan personal terhadap persepsi kemudahan penggunaan sistem (Y4) menghasilkan nilai koefisien jalur sebesar 0,484. Nilai $t$ Statistics didapat sebesar 5,534 (> t kritis 1,96), maka 
pengaruh keinovatifan personal terhadap persepsi kemudahan penggunaan sistem adalah signifikan. Hal ini menunjukkan bahwa keinovatifan personal berpengaruh positif dan signifikan terhadap persepsi kemudahan penggunaan sistem, dengan demikian Hipotesis keenam (H6) diterima. Hal ini memiliki makna bahwa semakin tinggi tingkat keinovatifan personal yang dimiliki pegawai, maka persepsi pegawai pada kemudahan penggunaan sistem Property Management akan semakin meningkat, begitu pula sebaliknya. Penelitian ini mendukung hasil penelitian Diksani dkk., (2014) dan Suardikha (2017) menyatakan dengan memiliki keinovatifan seorang pengguna sistem informasi akuntansi akan menggunakan aplikasi dan cara baru dalam melaksanakan tugasnya.

Pengujian hipotesis pada pengaruh budaya kerja terhadap kinerja manajemen (Y5) menghasilkan nilai koefisien jalur sebesar $-0,037$. Nilai $t$ Statistics didapat sebesar 1,446 (< t kritis 1,96), maka pengaruh budaya kerja terhadap kinerja manajemen adalah tidak signifikan. Hal ini menunjukkan bahwa budaya kerja tidak berpengaruh terhadap kinerja manajemen, dengan demikian Hipotesis ketujuh (H7) ditolak.

Hal ini memiliki makna bahwa baik buruknya budaya kerja dalam perusahaan, tidak akan mampu mempengaruhi kinerja manajemen yang dihasilkan oleh perusahaan. Hal ini disebabkan karena kinerja manajemen lebih besar dipengaruhi oleh variabel lain dibandingkankan budaya kerja.

Hasil tersebut mengindikasikan bahwa nilai - nilai yang terkandung dalam budaya kerja tidak dapat berdampak secara nyata terhadap kinerja 
manajemen. Apabila dikaitkan dengan karakteristik responden, data menunjukkan bahwa responden penelitian ini mayoritas sudah bekerja lebih dari 5 tahun hingga 10 tahun, sehingga pegawai cenderung sudah terbiasa dengan budaya kerja yang ada di Archipelago International Indonesia Area Bali, dan tidak terlalu memiliki dampak yang signifikan pada kinerja manajemen yang akan dihasilkan leh perusahaan.

Selain itu, pada penelitian ini faktor lainnya seperti persepsi atas kegunaan sisten dan persepsi kemudahan penggunaan sistem memiliki pegaruh yang signifikan pada kinerja manajemen. Hal ini berarti bahwa responden yang merupakan pegawai bagian accounting yang terlibat dalam penyusunan laporan manajemen secara langsung lebih dipengaruhi oleh persepsi kegunaan dan kemudahan penggunaan sistem Properti Management dibandingkan dengan budaya kerja, sebab laporan manajemen pada perusahaan Archipelago International Indonesia Area Bali lebih dominan di proses menggunakan sistem daripada budaya kerja. Penelitian ini mendukung hasil penelitian Hartono (2019) yang menyatakan bahwa budaya kerja tidak mempengaruhi kinerja. Hal ini disebabkan karena faktor yang mempengaruhi kinerja bukan hanya budaya kerja saja, akan tetapi lingkungan kerja, disiplin kerja dan faktor lainnya yang lebih mempengaruhi kinerja.

Pengujian hipotesis pada pengaruh persepsi kegunaan sistem terhadap kinerja manajemen (Y5) menghasilkan nilai koefisien jalur sebesar 0,657. Nilai $t$ Statistics didapat sebesar 8,564 (> t kritis 1,96), maka pengaruh persepsi kegunaan 
sistem terhadap kinerja manajemen adalah signifikan. Hal ini menunjukkan bahwa persepsi kegunaan sistem berpengaruh positif dan signifikan terhadap kinerja manajemen, dengan demikian Hipotesis kedelapan (H8) diterima.

Hal ini memiliki makna bahwa semakin tinggi persepsi kegunaan Sistem Property Management, maka kinerja manajemen yang dihasilkan akan semakin meningkat, begitu pula sebaliknya. Penelitian ini mendukung hasil penelitian Destiana (2012), Yudiastra \& Darma (2015), Suardhika (2017), Chirchir et al. (2019) dan Ganyam \& Ivungu (2019) yang menemukan hasil bahwa Persepsi penggunaan teknologi informasi memiliki pengaruh yang positif dan signifikan terhadap kinerja.

Pengujian hipotesis pada pengaruh persepsi kemudahan penggunaan sistem terhadap kinerja manajemen (Y5) menghasilkan nilai koefisien jalur sebesar 0,381. Nilai $t$ Statistics didapat sebesar 4,968 (> t kritis 1,96), maka pengaruh persepsi kemudahan penggunaan sistem terhadap kinerja manajemen adalah signifikan. Hal ini menunjukkan bahwa persepsi kemudahan penggunaan sistem berpengaruh positif dan signifikan terhadap kinerja manajemen, dengan demikian Hipotesis kesembilan (H9) diterima.

Hal ini memiliki makna bahwa semakin tinggi persepsi kemudahan penggunaan sistem Property Management, maka kinerja manajemen yang dihasilkan akan semakin meningkat, begitu pula sebaliknya. Penelitian ini mendukung hasil penelitian Suardhika (2017), Sukerta \& Darma (2014), Artawijaya \& Darma (2015), Chirchir et al. (2019) dan Ganyam \& Ivungu (2019) 
yang menemukan hasil bahwa efektivitas kemudahan penggunaan sistem berpengaruh pada kinerja karyawan ataupun kinerja sistem informasi akuntansi yang dihasilkan.

Tabel 4 berikut merupakan hasil dari uji pengaruh langsung dari masingmasing variabel yang diteliti.

Tabel 4.

Hasil Analisis Path

Tabel 4.

Path Coefficients

\begin{tabular}{|c|c|c|c|}
\hline Korelasi Antar Variabel & $\begin{array}{l}\text { Koefisien } \\
\text { Path }\end{array}$ & T Statistic & Keterangan \\
\hline $\begin{array}{l}\text { Budaya kerja }\left(\mathrm{X}_{1}\right) \rightarrow \text { Keyakinan atas sistem } \\
\text { (Y1) }\end{array}$ & 0,380 & 2,390 & Signifikan \\
\hline $\begin{array}{l}\text { Budaya kerja }\left(\mathrm{X}_{1}\right) \rightarrow \text { Keinovatifan personal } \\
\left(\mathrm{Y}_{2}\right)\end{array}$ & 0,525 & 5,660 & Signifikan \\
\hline $\begin{array}{l}\text { Keyakinan atas sistem }(\mathrm{Y} 1) \rightarrow \text { Persepsi } \\
\text { Kegunaan sistem (Y3) }\end{array}$ & 0,222 & 2,221 & Signifikan \\
\hline $\begin{array}{l}\text { Keinovatifan personal }\left(\mathrm{X}_{3}\right) \rightarrow \text { Persepsi } \\
\text { Kegunaan sistem (Y3) }\end{array}$ & 0,670 & 6,554 & Signifikan \\
\hline $\begin{array}{l}\text { Keyakinan atas sistem }(\mathrm{Y} 1) \rightarrow \text { Persepsi } \\
\text { Kemudahan penggunaan sistem }(\mathrm{Y} 4)\end{array}$ & 0,468 & 4,578 & Signifikan \\
\hline $\begin{array}{l}\text { Keinovatifan personal }\left(\mathrm{X}_{3}\right) \rightarrow \text { Persepsi } \\
\text { Kemudahan penggunaan sistem }(\mathrm{Y} 4)\end{array}$ & 0,484 & 5,534 & Signifikan \\
\hline $\begin{array}{l}\text { Budaya kerja }\left(\mathrm{X}_{1}\right) \rightarrow \text { Kinerja manajemen } \\
(\mathrm{Y} 5)\end{array}$ & $-0,037$ & 1,446 & $\begin{array}{l}\text { Tidak } \\
\text { Signifikan }\end{array}$ \\
\hline $\begin{array}{l}\text { Persepsi Kegunaan sistem (Y3) } \rightarrow \text { Kinerja } \\
\text { manajemen (Y5) }\end{array}$ & 0,657 & 8,564 & Signifikan \\
\hline $\begin{array}{l}\text { Persepsi Kemudahan penggunaan sistem (Y4) } \\
\rightarrow \text { Kinerja manajemen (Y5) }\end{array}$ & 0,381 & 4,968 & Signifikan \\
\hline
\end{tabular}

Sumber : Data diolah, 2020

\section{SIMPULAN DAN SARAN}

Kesimpulan dalam penelitian ini adalah budaya kerja berpengaruh positif dan signifikan terhadap keyakinan atas sistem, budaya kerja berpengaruh positif dan signifikan terhadap keinovatifan personal, keyakinan atas sistem berpengaruh positif dan signifikan terhadap persepsi kegunaan sistem, keinovatifan personal 
berpengaruh positif dan signifikan terhadap persepsi kegunaan sistem, keyakinan atas sistem berpengaruh positif dan signifikan terhadap persepsi kemudahan penggunaan sistem, keinovatifan personal berpengaruh positif dan signifikan terhadap persepsi kemudahan penggunaan sistem, budaya kerja terhadap kinerja keuangan adalah tidak signifikan, persepsi kegunaan sistem berpengaruh positif dan signifikan terhadap kinerja keuangan, Persepsi kemudahan penggunaan sistem berpengaruh positif dan signifikan terhadap kinerja keuangan,

Saran untuk dapat meningkatkan budaya kerja yang lebih baik, maka disarankan agar pemimpin perusahaan untuk mengevaluasi kembali terkait budaya kepemimpinannya agar menjadi lebih bijaksana seperti bersedia mendengarkan keluhan pegawai, kemudian memberi kesempatan bagi seluruh pegawainya untuk berpendapat secara adil. Kemudian dalam upaya meningkatkan keyakinan atas sistem ke arah yang lebih baik, maka Archipelago International Indonesia Area Bali diharapkan dapat memberikan pelatihan bagi pegawai yang masih kurang percaya diri dalam menggunakan sistem manajemen perusahaan, khususnya pada pegawai yang baru bergabung dengan perusahaan.

\section{REFERENSI}

Artawijaya, I Gusti Putu Anom., dan Gede Sri Darma. 2015. Evaluation The Effectivity Of Performance Management Online System To Improving The Employees Performance. Journal Management and Busines.12(2), 7389.

Binyamin, S., Rutter, M., \& Smith, S. 2016. The utilization of system usability scale in learning management systems: a case study of Jeddah Community College. In ICERI2016 Proceedings, (5314-5323).

Chirchir, Habiba. 2017. Trabecular Bone Fraction Variation In Modern Humans, 
Fossil Hominins And Other Primates. Journal International Record. 302(2), 288-305.

Destiana, B. (2012). Analisis Faktor-faktor yang Mempengaruhi Minat Pemanfaatan Sistem Informasi dan Penggunaan Sistem Informasi (Studi Empiris pada Perusahaan Manufaktur yang Terdaftar di Bursa Efek Jakarta). Skripsi Universitas Negeri Yogyakarta.

Diksani, I Komang Ari., Ni Kadek Sinarwati dan Nyoman Ari Surya Darmawan. 2014. Pengaruh Keyakinan Diri Atas Komputer, Keinovatifan Personal, Persepsi Kegunaan, Dan Persepsi Kemudahan Penggunaan Terhadap Penggunaan Sistem Informasi Akuntansi (Studi Pada Kantor Cabang Utama Bank Central Asia di Singaraja). e-Journal Ak Universitas Pendidikan Ganesha. 2(1), 1-10.

Djuanda, Vincentius David., dan Josua Tarigan. 2016. Pengaruh Budaya Organisasi terhadap Kinerja Manajemen melalui Perilaku Manajer atas Isu Manajemen Lingkungan sebagai Variabel Interveningnya. Bussiness Accounting Review, 4(1), 61-72.

Ganyam, Amos., and John Ayoor Ivungu. 2019. Effect of Accounting Information System on Financial Performance of Firms: A Review of Literature. Journal of Business and Management (IOSR-JBM), 2(5), 39-49.

Oliveira, Rodrigo., Mauro Cherubini and Nuria Oliver. 2017. Influence of Usability on Customer Satisfaction: A Case Study on Mobile Phone Services. Journal University of Mexico. 1-6

Raddaha, Ahmad H Abu. 2017. Nurses' perceptions about and confidence in using an electronic medical record system. Proceedings of Singapore Healthcare. 27(2), 110-117.

Suardikha, Sadha. 2017. Pengaruh Implementasi Budaya Tri Hita Karana Terhadap Penggunaan Sistem Informasi Akuntansi Dimediasi Keyakinan Diri Atas Komputer, Keinovatifan Personal, Persepsi Kegunaan, dan Persepsi Kemudahan Penggunaan Pada Bank Perkreditan Rakyat di Bali (Studi pada Bank Perkreditan Rakyat di Provinsi Bali), Journal SNA XV Universitas Lambung Mangkurat Banjarmasin. 10(1).1-45.

Sudaryono, Eko Arief dan Astuti. 2015. Pengaruh Computer Anxiety Terhadap Keahlian Karyawan Bagian Akuntansi Dalam Menggunakan Komputer. Joutnal SNA VIII Solo. 5(1), 894-902.

Sukerta, I Putu Gde., dan Gede Sri Darma. 2014. Application Of Information Technology Integrated System To Improving The Quality And Financial Performance. Jurnal Manajemen dan Bisnis. 11(2), 72-88.

Valencia, Julia C Naranjo, Daniel Jimenez and Raquel Sanz-Valle. 2017. Organizational culture and radical innovation: Does innovative behavior 
Budi Utomo dan I.B.Teddy Prianthara. Analisis Model Penerimaan Teknologi.

mediate this relationship?. Journal Creativity and inovation management. 26(4), 407-41.

Yudiasta, Putu Panda dan Gede Sri Darma. 2015. Pengaruh Penggunaan Teknologi Informasi, Disiplin Kerja, Insentif, Turnover Terhadap Kinerja Pegawai. Jurnal Manajemen dan Bisnis. 12(1), 151-176.

Zeinabi, H., and M. Sheikh. 2016. Evaluate The Effect Of Perceived Ease And Usefulness,Customer's Awareness And Confidence By Mobile Bank On Tendency To Use (Intended Use) Of Mobile Bank's System (Case Study Of Customers Of Khuzestan's Tejarat Bankbranches). Journal of Fundamental and Applied Sciences. 8(2), 1838-1851. 